\title{
Influence of the Surface Treatment of Hardened Cement Mortar with Colloidal Nano-Silica and TEOS
}

\author{
Pengkun Hou, Xin Cheng, and Zonghui Zhou \\ School of Materials Science and Engineering, University of Jinan, Shandong, 250022, China \\ Shandong Provincial Key Laboratory of Preparation and Measurement of \\ Building Materials, Jinan, Shandong 250022, China
}

\begin{abstract}
Two types of silicate material, tetraethoxysilane (TEOS) and colloidal nanoSiO ${ }_{2}$ (CNS), were applied for surface treatment of hardened cement mortar by exploring their filling and pozzolanic reactivity to make the surface compacter. Results showed that the water adsorption coefficient, the water vapor transmission rate, and the water penetration depth were reduced when CNS and TEOS were applied onto the surface of hardened cement mortar, and TEOS exhibits a superior effect on surface treatment, making the mass-transport rate and extent smaller than CNS does.
\end{abstract}

\section{INTRODUCTION}

The deterioration of concrete is usually caused by both internal and external factors. Detrimental elements always penetrate into concrete from the surface of the concrete, so a better developed concrete surface property will benefit the whole property of concrete greatly. Researchers have been working on exploring surface-treatment agents for quite a long time, and more recently, a silicate material, nano-silica has gain much attention. In last decade, nano-silica has been intensively used in cement and concrete (Hou, 2014). It is very fine in particle size (about several to $100 \mathrm{~nm}$ ), and many works have proved that it has an extremely high pozzolanic reactivity. It is shown in our previous work that the pozzolanic reaction rate constant of nanoSiO ${ }_{2}$ is about one order of magnitude bigger than that of silica fume (Singh, Karade, Bhattacharyya, Yousuf, \& Ahalawat, 2013). Hou's work also found that the hydration products of nanoSiO ${ }_{2}$ are more compact than that of silica fume (Hou, 2012). By realizing that the high pozzolanic reactivity of the material, as well as the nano-sized particle size feature of nanSiO ${ }_{2}$, which would favor its penetration into the porous structure on the surface, could be favorable for its application in making a compact surface structure, some researchers have used it for surface treatment of hardened cementitious materials. Very recently, an another type of silicate material, tetraethoxysilane (TEOS), which hydrolyzes in the pores of cementitious materials and forms nano-sized silicate cluster, has been used for surface treatment. Sandrolini and his co-workers' results showed that TEOS was pozzolanic reactive (Mondal, Shah, Marks, \& Gaitero, 2010). In this paper, the effects of surface treatment of hardened cement mortar with CNS and TEOS are going to be compared through testing the water vapor transmission rate, water adsorption rate, and water penetration depth on mortar samples.

\section{EXPERIMENTAL}

\subsection{Raw materials}

Ordinary Portland cement complying with Chinese standard GB 175-2007 was used in this work, and its physiochemical properties are listed in Table 1. Commercially available CNS with a mean particle size of $10 \mathrm{~nm}$ and solid content of $30 \%$ was used. Chemical grade tetraethoxysilane (TEOS) was used, and its content was $30 \%$ by mass.

Table 1. Physiochemical properties of cement.

\begin{tabular}{cccccccc}
\hline $\mathrm{SiO}_{2}$ & $\mathrm{Al}_{2} \mathrm{O}_{3}$ & $\mathrm{Fe}_{2} \mathrm{O}_{3}$ & $\mathrm{SO}_{3}$ & $\mathrm{CaO}$ & $\mathrm{MgO}$ & LOI & $\begin{array}{c}28 \text { days compr. } \\
\text { Str. (MPa) }\end{array}$ \\
\hline 21.1 & 4.7 & 3.5 & 3.3 & 62.9 & 2.8 & 1.1 & 50.1 \\
\hline
\end{tabular}

\subsection{Sample preparation}

In order to get a clear picture of the influence of surface treatment on the water adsorption properties of the cementitious materials, paste samples with the water to cement ratio of 0.6 were made in this work. Before adding water into cement, we mixed thickening agent and defoaming agent with cement and stirred the mix to be well dispersed. After mixing the cement paste for at least $5 \mathrm{~min}$, samples were cast in the $4 \mathrm{~cm} \times 4 \mathrm{~cm} \times 16 \mathrm{~cm}$ mold. The samples were cured in the $20^{\circ} \mathrm{C} / 95 \% \mathrm{RH}$ chamber for 2 days before demolding. The samples were then kept in the chamber for a certain time before test. Mortar samples 
with the water to cement ratios of 0.4 and 0.6 that used for measuring water vapor transmission coefficient were molded in the PVC tubs with a diameter of $8 \mathrm{~cm}$ and at a binder to sand ratio of 1:3. After casting for 1 day, mortar samples were demolded and then cured in $20^{\circ} \mathrm{C} / 95 \% \mathrm{RH}$ chamber.

\subsection{Water adsorption property}

Samples for the water adsorption measurement were made into small pieces with the size of $4 \mathrm{~cm} \times 4 \mathrm{~cm} \times 2 \mathrm{~cm}$. After the samples were treated with water, TEOS and CNS by soaking technique, they were cured in $20^{\circ} \mathrm{C} / 95 \% \mathrm{RH}$ for 14 days before water absorption testing. Samples were oven dried at $60^{\circ} \mathrm{C}$ for 2 days before measurement. During the measurement, only one side of the samples was left unsealed with epoxy resin. The unsealed side of the sample was immerged in water for a certain time, and samples were weighed in the saturateddry condition. Water absorption ratio was calculated by dividing the surface area (in square centimeters) with the weight growth (in milligrams) of the sample. For each test, the water absorption ratios of three samples at 10, 20, 40, $90 \mathrm{~min}$, and $24 \mathrm{~h}$ water-soaking time were tested and averaged to be taken as the representative value. The initial water absorption coefficient, i.e., slope of the water absorption ratio vs. square root of time (in seconds) at the beginning of water absorption described in Sandrolini, Franzoni, and Pigino (2012) was adopted to reflect the water transport properties.

\subsection{Water vapor transmission property}

Mortar samples used for measuring the water vapor transmission property were cut into slice with a thickness of $1.5 \mathrm{~cm}$, and then treated with water, CNS, and TEOS. Before water vapor transmission property measurement, samples were cured under $20^{\circ} \mathrm{C} / 95 \% \mathrm{RH}$ for 7 and 36 days. In order to reflect the water vapor transport properties of mortar, "Wetcup" method (Khatib \& Mangat, 1995) was used. The principle of the "wet-cup" method is that, when the water vapor in the wet cup transmits from the high humidity to low humidity environment, the weight of the cup will decrease. The weight loss rate can be recorded to show the densification extent of the sample. In this work, the humidity gradient was generated by the pure water (100\% humidity) and saturated $\mathrm{KBr}$ solution ( $80 \%$ humidity). And then the water loss of the cup due to transmission of vapor from high humidity to low humidity was recorded and slope of the weight loss vs. time curve was used to reflect water vapor transport property of the mortar sample. Before measurements, the samples were kept in the condition of $70 \% \mathrm{RH}$ in room temperature (about $25^{\circ} \mathrm{C}$ ) for 1 day.

\subsection{Mortar permeability test}

Mortar samples for water permeability measurement were cured under $20^{\circ} \mathrm{C} / 95 \% \mathrm{RH}$ for 7 days after casting. The following procedure was used for sample treatment. Samples were divided into three groups (group 1, 2, and 3), and there were three samples in each group. Groups 1, 2, and 3 were soaked in water, CNS, and TEOS, respectively, for $1 \mathrm{~h}$, and then all the samples were moved into curing chamber and cured for different time before measurement. During the water permeability test of the samples, the water pressure got started from $0.2 \mathrm{MPa}$ and increased at a rate of $0.2 \mathrm{MPa} / \mathrm{h}$, when the pressure reached $2 \mathrm{MPa}$, the pressure was kept constant for another $15 \mathrm{~h}$. Then, samples were taken out and cut into half for the measurement of the penetration depth of water.

\section{RESULTS AND DISCUSSIONS}

\subsection{Initial water adsorption coefficient}

The water adsorption coefficient of mortar sample that was treated by water, TEOS, and CNS were shown in Table 2, it demonstrates that the water absorption coefficient of samples treated by CNS and TEOS were reduced by 22.7 and $68 \%$ compared to the control sample. This demonstrates that the porosity of mortar sample was reduced by these two agents, and a greater pore-fining effect is seen in TEOS-treated sample. It was reported in our previous work that the pozzolanic reaction happened between nano-silica/ TEOS leading to the production of additional C-S-H gel would be favorable for the pore-fining effect (ASTM, 2000). At the same time, the pore-fining effect of the nano-particles would also contribute to the reduction of the water adsorption property. When comparing the reduction degree of the initial water adsorption coefficient in Table 2, we can see that TEOS is more effective than CNS in the reducing the water absorption coefficient. This could be attributed to the fact that TEOS is more permeable than CNS into the pores.

Table 2. Influences of CNS and TEOS on the initial water adsorption coefficient of cement mortar $\left(\mathrm{g} / \mathrm{cm}^{2} \cdot \mathrm{s} 1 / 2,28\right.$ days old, samples were cured in standard curing condition for 14 days after surface treatment with CNS and TEOS).

\begin{tabular}{ccccc}
\hline w/c & $\begin{array}{c}\text { Curing regime after } \\
\text { surface treatment }\end{array}$ & Control & $\begin{array}{c}\text { CNS } \\
\text { treated }\end{array}$ & $\begin{array}{c}\text { TEOS } \\
\text { treated }\end{array}$ \\
\hline 0.6 & $20^{\circ} \mathrm{C} / 95 \% \mathrm{RH} / 14$ days & 0.381 & 0.252 & 0.122 \\
\hline
\end{tabular}

\subsection{Water vapor transmission coefficient}

Influences of surface treatment of cement mortar with CNS and TEOS on the water vapor transmission property are demonstrated in Figure 1. It shows that the weight of the cup decreases linearly with time and 

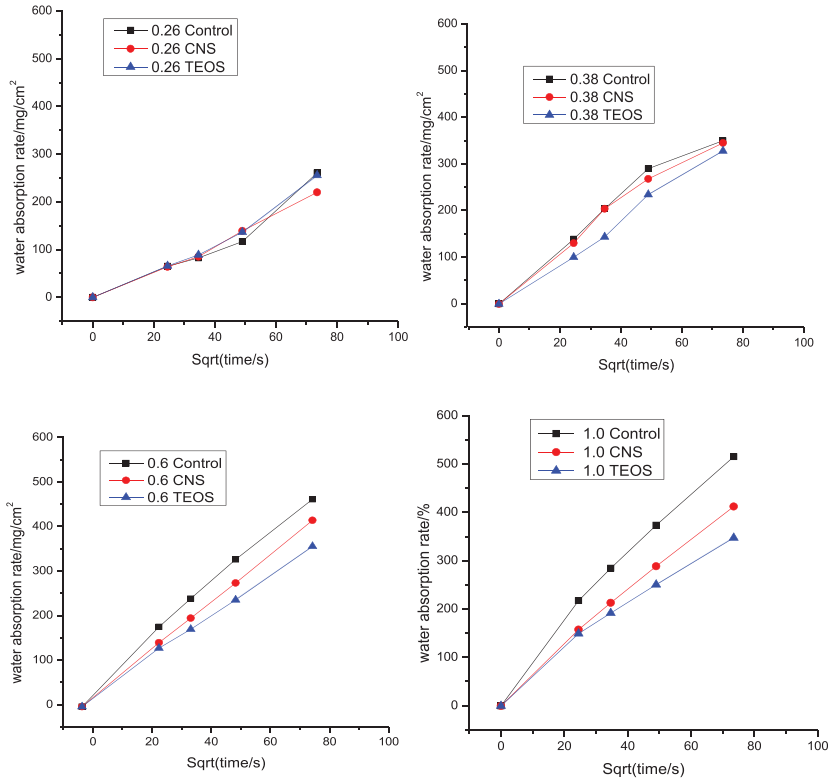

Figure 1. The influence on the water absorption ratios when CNS and TEOS treated on the surface of the cement-based materials with different $\mathrm{w} / \mathrm{c}$ ratios.

the slope of the scatter graph after equilibrium reflects the water vapor transmission capability through the mortar sample. A greater slope inflects a bigger water vapor transmission coefficient.

From Figure 1, it can be seen that both CNS and TEOS can lower the water vapor transmission coefficient of the mortar sample, i.e., the reduction of the slope of the weight vs. time scatter curve, the variations of the reduction extents of these coefficients can reflect the difference of the porerefining characteristics of CNS and TEOS. Figure 1 shows that the water vapor transmission coefficients of CNS-treated and TEOS-treated samples were reduced by 6.3 and $64.0 \%$ to the control sample, indicating that a slight pore refining effect of CNS on the sample can be obtained, while a significant effect can be obtained when TEOS was applied onto the surface. These results show the same trend as shown in Table 2.

\subsection{Water penetration test of mortar}

The water penetration depth of mortar samples before and after surface treatment was used to reflect the influence of surface treatment. Figure 2 shows the scatter graph of the penetration depth of mortar sample. At least the penetration depth at 10 locations was measured and averaged to be taken as the penetration depth value. In this work, the water penetration coefficient, i.e., value of the penetration depth of surface-treated sample divided by that of the control sample, was used and the results are shown in Table 3.

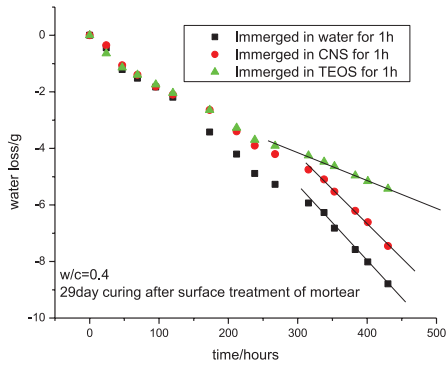

Figure 2. Effects of surface treatment of cement mortar with CNS and TEOS on the water vapor transmission property $(\mathrm{w} / \mathrm{c}=0.4$ mortar, curing for 36 days).

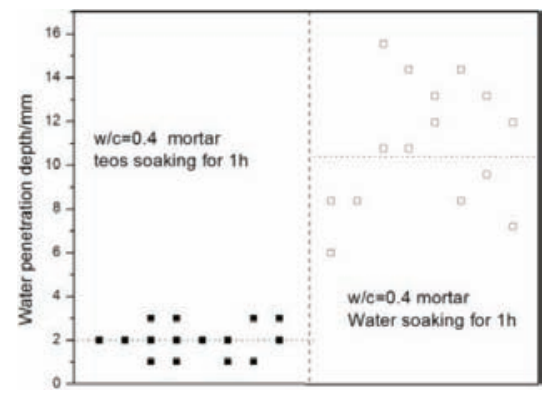

Figure 3. Comparison of water penetration depth after treating with CNS and TEOS.

Table 3. Water penetration coefficient of mortar sample treated with CNS and TEOS.

\begin{tabular}{ccccccc}
\hline w/c & \multicolumn{4}{c}{$\mathbf{0 . 4}$} & \multicolumn{2}{c}{$\mathbf{0 . 6}$} \\
\hline Treating & CNS/ & TEOS/ & CNS/ & TEOS/ & CNS/ & TEOS/ \\
& $1 \mathrm{~h}$ & $1 \mathrm{~h}$ & $1 \mathrm{~h}$ & $1 \mathrm{~h}$ & $1 \mathrm{~h}$ & $1 \mathrm{~h}$ \\
Curing & 24 days & 24 days & 38 days & 38 days & 40 days & 40 days \\
Coeff. & 0.75 & 0.47 & 0.28 & 0.2 & 0.63 & 0.36 \\
\hline
\end{tabular}

It shows in Table 3 that the penetration coefficients of samples that were treated with CNS and TEOS are all smaller than 1, indicating an improvement of the compactness of the treated samples. And this compiles well with those shown in the previous sections. In regard of the reduction extent of the penetration coefficient to that of 1 , it shows that TEOS is more capable in reducing the water penetration depth. It can be seen that the penetration coefficient of CNS-treated samples are 37, 29, and $43 \%$ smaller than TEOS-treated samples for $\mathrm{w} / \mathrm{c}=0.4$, curing time $=24$ days; $\mathrm{w} / \mathrm{c}=0.4$, curing time $=38$ days; $w / c=0.6$, curing time $=40$ days samples.

\section{SUMMARY}

(1) Both TEOS and CNS can reduce the water adsorption ratio, water vapor transmission, and water penetration properties of cement mortar when they are surface treated and 
(2) TEOS is more effective than CNS in making the surface of hardened cement mortar compacter, and this could be partially due to its superior penetration capability into mortar, which is still under research.

\section{ACKNOWLEDGMENTS}

Supports from Development Program ("863 Program," 2015AA034701) and Natural Science Foundations of China (Grant Nos. 51302105 and 51272092) and National High Technology Research are greatly acknowledged.

\section{REFERENCES}

ASTM. (2000). ASTM E96 - 00 standard test methods for water vapor transmission of materials. West Conshohocken, PA: ASTM.

Hou, P. (2012). Modification effects nanoSiO ${ }_{2}$ on the hydration and hardening properties of cement-fly ash blends (PhD thesis, Chongqing University), Chongqing, China.
Hou, P. (2014). Effects and mechanisms of surface treatment of hardened cement-based materials with colloidal nanoSiO ${ }_{2}$ and its precursor. Construction and Building Materials, 53, 66-73.

Khatib, J., \& Mangat, P. (1995). Absorption characteristics of concrete as a function of location relative to casting position. Cement and Concrete Research, 25(5), 999-1010.

Mondal, P., Shah, S. P., Marks, L. D., \& Gaitero, J. J. (2010). Comparative study of the effects of microsilica and nanosilica in concrete. Transportion Research Record, 2141, 6-9.

Sandrolini, F., Franzoni, E., \& Pigino, B. (2012). Ethyl silicate for surface treatment of concrete - Part I: Pozzolanic effect of ethyl silicate. Cement and Concrete Composites, 34, 306-312.

Singh, L. P., Karade, S. R., Bhattacharyya, S. K., Yousuf, M. M., \& Ahalawat, S. (2013). Beneficial role of nanosilica in cement based materials A review. Construction and Building Materials, 47, 1069-1077. 